\title{
On winding Electromagnets
}

This content has been downloaded from IOPscience. Please scroll down to see the full text. 1882 Proc. Phys. Soc. London 5230

(http://iopscience.iop.org/1478-7814/5/1/327)

View the table of contents for this issue, or go to the journal homepage for more

Download details:

IP Address: 142.132.1.147

This content was downloaded on 09/09/2015 at 18:10

Please note that terms and conditions apply. 
(3) Every colour when intensely lighted up appears white (von Kries, p. 81). A not improbable explanation of this seems to be that the other colour-sensas are only capable of being affected by light to a limited extent as compared with the white colour-sense.

(4) In cases of atrophy of the optic nerve the perceptions of different colours are gradually lost, until at length every colour appears grey (von Kries, p 154).

(5) There are also cases of total colour-blindness from birth, when every thing appears of the same colour with only different degrees of light and darkness. When this affects both eyes completely, it is of course impossible to predicate with absolute certainty what colour is perceived. But Becker (Gräf"s Archiv, vol. xxv.) describes a case where only one eye was so affected, the other having normal vision; and I have seen another case described in which one half of each eye was completely colour-blind, the other half being normal. In each of these cases the colour-blind vision was of white. This white vision must have been arrived at either through the other colour-senses having been lost, leaving a white coloursense behind, or through their having been modified into white.

XXVI. On winding Electromagnets. By Professors W. E. Ayrton, F.R.S., and John Perry, M.E.*

[Plates X. \& XI.]

THE following experiments were made to determine which mode of winding a given length of wire on an iron bar gave the strongest electromagnet for the same current. Four bars of iron, each 12 inches long, were cut from the same rod 3 inch thick; and an exactly equal length of wire was wound on the four bars respectively, in the following way :-

1. Wire wound equally over the whole length (Pl. X. fig. 1).

2. Wire coned towards each end (fig. 2).

3. Wire wound equally over half the iron bar, leaving the other end bare (fig. 3).

* Read December 9, 1882. 
Frow, Phys, Sor. Vol.5. Pl.X

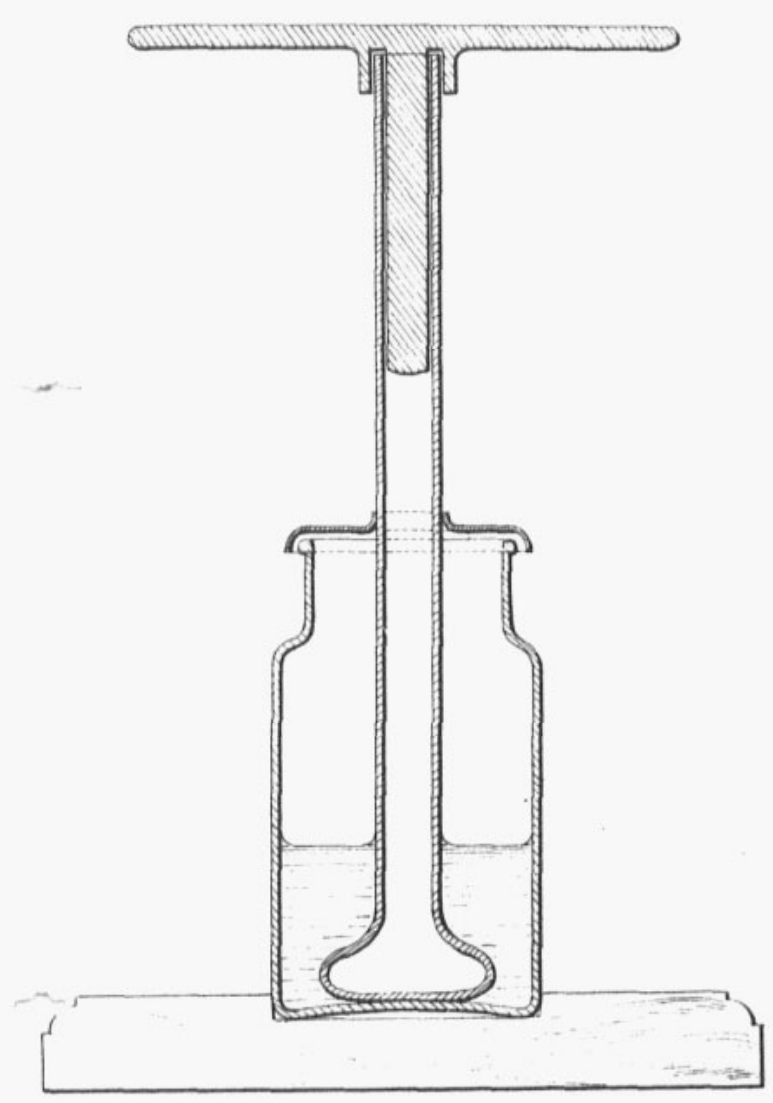

15.1

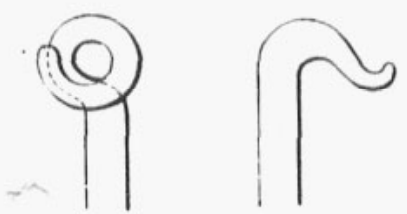

ig.2. Fig.3.

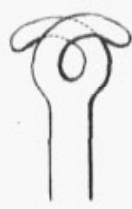

Fig.4.

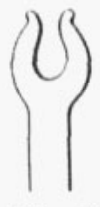

Fig. 5 .

cale 2 .

Ir)tem Brom.lith. 
Proo.Phys. Soc.Vol.5.Pl.X.
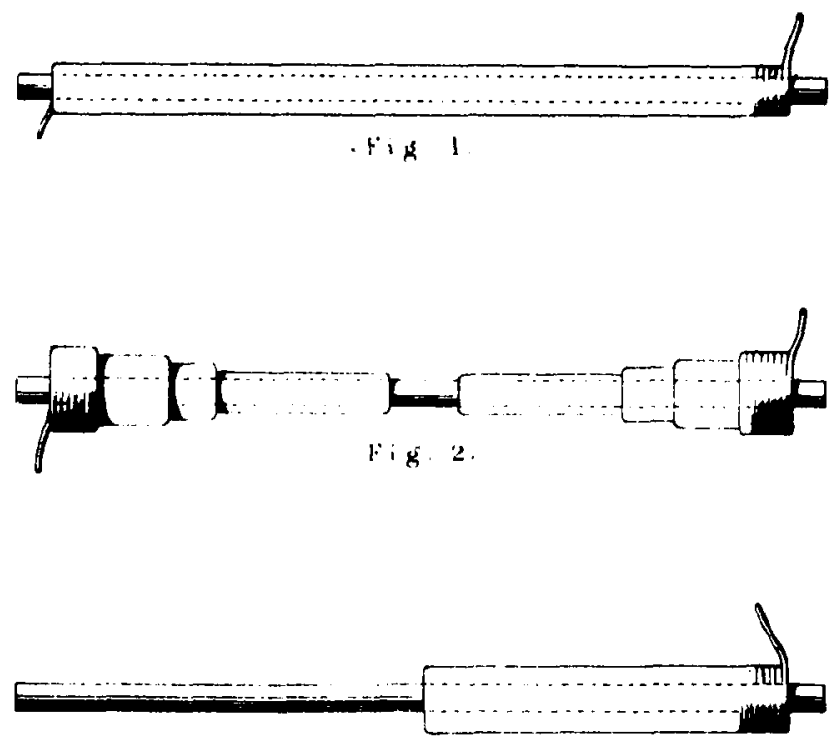

'́j $\mathrm{g} .3$.

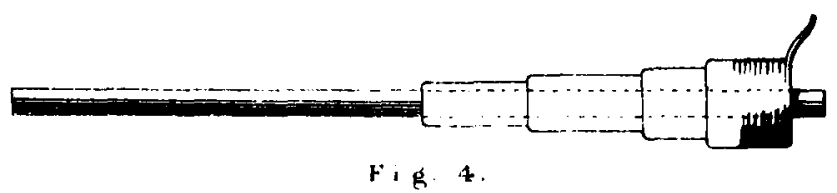

"WINDING ELECTROMAGNETS".

$$
\text { CURVES BETWEEN }
$$

TANGENT OF DEFLECTION OF NEEOLE AND

DISTANCE OF CORE FROM NEEDLE.

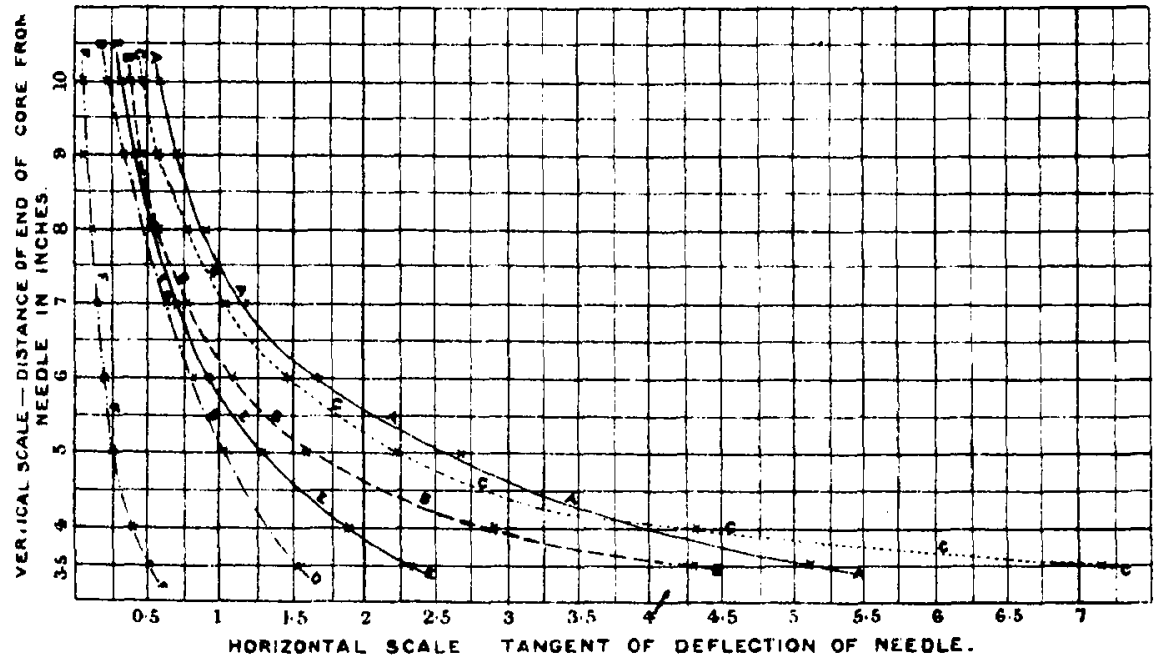

Fig. 5 


\section{"Winding Electromagnets."}

LINES OF FORCE AS SHOWN BY IRON FILINGS.

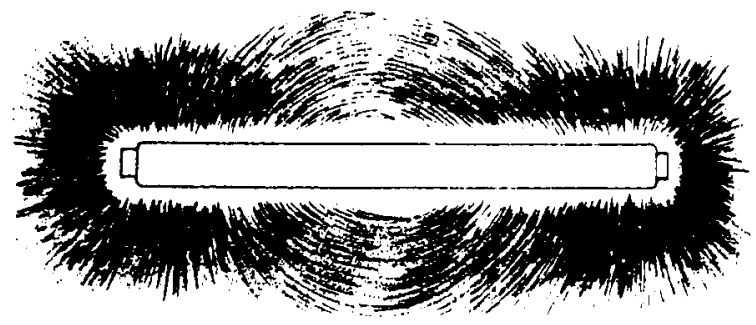

N: 6.

WOUND REGULARLY OVER WHOLE LENGTH

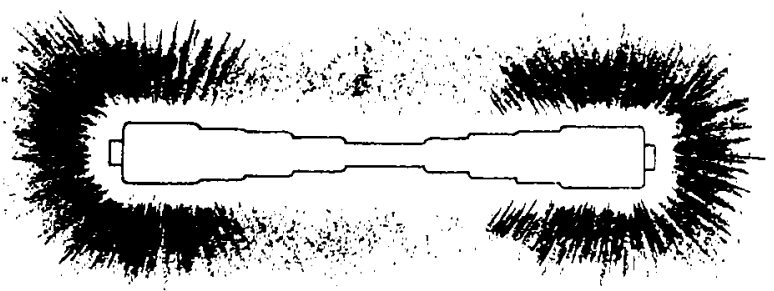

No 7.

WOUND CONED TOWARDS EACH END.
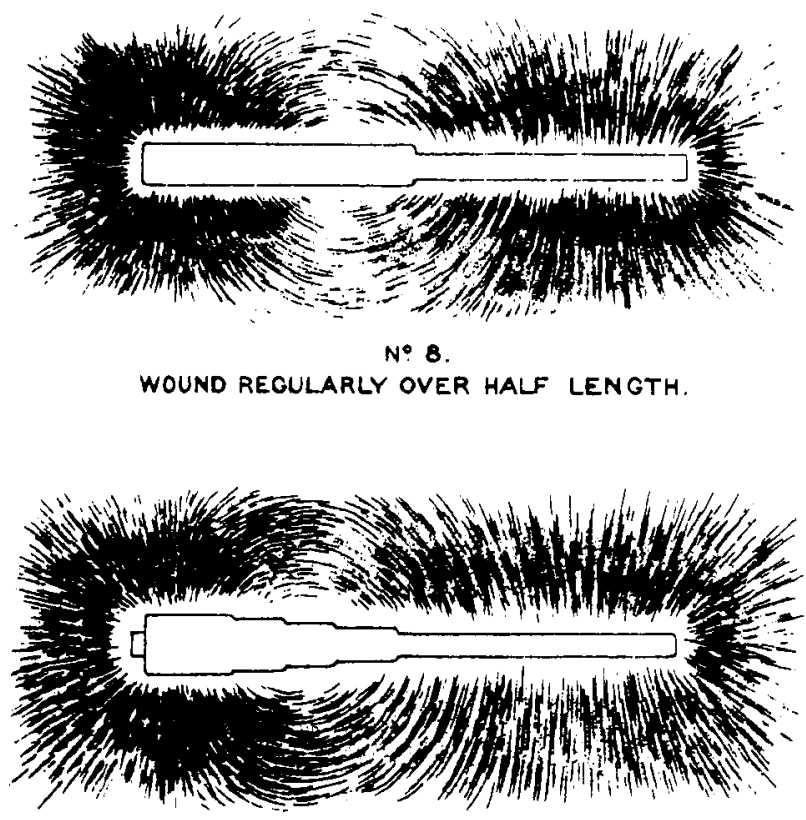

N: 9.

WOUND CONED OVER HALF LENGTH. 
4. Wire wound on one half but coned towards the end (fig. 4).

Electromagnet No. 1 was put so that its axis was at right angles to the axis of a small magnetic needle and passed through the point of suspension of the needle, which was suspended so as to move freely in a horizontai plane, and far enough away that the magnetic field due to the electromagnet No. 1, when magnetized by passing a current through it, was nearly constant orer that portion of the field in which the little suspended needle moved when deflected. A constant current was now passed through the coil on No. 1, and the deflection of the little needle observed when No. $_{1} 1$ was placed at different distances from the centre of the test-needle, the axis of No. 1, however, always remaining in the same line. Under these circumstances it is well known that the strength of the field produced by No. 1 at the centre of the test. needle is approximately proportional to the tangent of its deflection. Experiments were now made in a sinilar way with electromagnet No. 2, and with each end of No. 3 and of No. 4, the same current as was employed with electromagnet No.1 being used in all cases, and which was much below the saturating current.

The results obtained are given in the accompanying table, and are shown plotted in the accompanying curres (fig. 5), vertical distances representing the distance between the near end of the electromagnet and the centre of the test-needle, and horizontal distances the tangents of the deflection of the test-needle: A A A is that for No. 1; B B B B for No. 2; $C \mathrm{CCC}$ for the covered end of No. $3 ; \mathrm{DDDD}$ for the uncovered end of No. 3; EEEE for the covered end of No. 4 ; and F F F F' for the uncovered end of No. 4.

\begin{tabular}{|c|c|c|c|c|c|c|c|c|c|c|c|c|}
\hline \multirow{3}{*}{$\begin{array}{l}\text { Jistance in } \\
\text { inches between } \\
\text { the near end of } \\
\text { the bar and the } \\
\text { centre of the } \\
\text { test-needle. }\end{array}$} & \multirow{2}{*}{\multicolumn{2}{|c|}{ No. 1.}} & \multirow{2}{*}{\multicolumn{2}{|c|}{ No. 2.}} & \multicolumn{4}{|c|}{ No. 3.} & \multicolumn{4}{|c|}{ No. 4.} \\
\hline & & & & & $\begin{array}{l}\text { Cor } \\
\text { en }\end{array}$ & $\begin{array}{l}\text { ered } \\
\text { hal. }\end{array}$ & & $\begin{array}{l}\text { are } \\
\text { d. }\end{array}$ & $\begin{array}{l}\text { Cor } \\
\text { en }\end{array}$ & $\begin{array}{l}\text { rered } \\
\text { nd. }\end{array}$ & & $\begin{array}{l}\text { are } \\
\text { d. }\end{array}$ \\
\hline & Def. & $\Gamma$ an. & Def. & Tan. & Def. & Tan. & Def. & Tan. & Def. & Tan. & Def. & Tan. \\
\hline $3 \frac{1}{2}$ & $79^{\circ}$ & $5 \cdot 14$ & $77^{\circ}$ & 433 & $82^{\circ}$ & $7 \cdot 12$ & $57^{\circ}$ & 1.54 & $67^{\circ}$ & 230 & $27^{\circ}$ & $0.57 \mid$ \\
\hline 4 & 77 & 433 & 71 & 29 & 77 & $4 \cdot 33$ & 53 & 133 & 62 & 1.88 & 21 & \\
\hline 5 & $69 !$ & 265 & 58 & $16 i$ & $(36)$ & $2 \cdot 24$ & 46 & 1.04 & 52 & $1 \cdot 28$ & 14 & 0.28 \\
\hline 6 & 59 & $1 \cdot 66$ & 47 & 1.07 & 56 & 1.48 & 39 & 0.81 & 43 & 0.93 & 11 & 0.1 \\
\hline 7 & 50 & $1 \cdot 19$ & 37 & 076 & 46 & $1 \cdot 04$ & 32 & 0.62 & 36 & 073 & 9 & \\
\hline 8 & 42 & 09 & 30 & 0.58 & $37 \frac{1}{2}$ & 0.79 & $27 \frac{1}{2}$ & 0.52 & 29 & $0 \cdot 56$ & 7 & 0.12 \\
\hline 9 & 35 & $0 \cdot 7$ & 24 & 0.46 & 30 & $|0.58|$ & $18^{\circ}$ & 0.32 & 22 & 0.48 & 4 & 0.07 \\
\hline 10 & 30 & 0.58 & 20 & 0.36 & 25 & 0.47 & 13 & 0.23 & 17 & 0.31 & 3 & 0.05 \\
\hline
\end{tabular}


To ascertain the distribution of the lines of force, iron filings were sprinkled on paraffined paper, and the positions the filings took up fixed by the paraffin being softened by a heated piece of copper being passed over the paper at a short distance above it. These fields of force are shown in the diagrams $6,7,8$, and 9 (Pl. XI.). From the curves in fig. 5 and from the iron-filing curves it is seen that the effect of coning the wire is to produce a strong field very near the pole, but that the force falls off very rapidly as the distance from the pole increases. With No. 2 magnet, for instance, the field between the poles is so weak that scarcely any definite arrangement of filings is traceable in the diagram 7 corresponding with it.

From the curves in fig. 5 it is seen that, at considerable distances from the end of the electromagnet, the uniformly coiled magnet No. 1 produces the most powerful field, while for points nearer the magnet, but still at a distance of about 3 inches from it, the covered end of No. 3 magnet, corresponding with the curve C C C, produces the strongest field, the next strongest being produced by the magnet No. 2 with the wire coned towards each end, since obviously the curve $\mathrm{BBB}$ cuts the curve $\mathrm{AAA}$ at a point corresponding with a distance of about 3 inches from the end of the magnet. For distances very close to the magnet, this method of experimenting cannot, of course, be employed to measure the resultant force accurately; and hence ubservations by this method at distances of less than $3 \frac{1}{2}$ inches from the end of the magnet to the centre of the oscillating needle were not made, and conclusions as to the resultant magnetic force very close to the poles must, of course, not be drawn from the curves in fig. 4 .

Returning to the curves taken up by the iron filings, we see that No. 1 magnet gives an arrangement similar to that of an ordinary regularly magnetized bar-magnet. With No. 2 the lines around the poles are similar to those of No. 1, but the field between the poles is very weak. Magnets Nos. 3 and 4 give very similar figures, showing a very peculiar distribution of force. There is a great concentration of the lines at the pole corresponding to the half of the iron which is covered with wire; but the unwound end seems to form a 
long weak pole, with its maximum force near the centre of the bar, $i$. e. at the inner end of the coil,- - the differences between these two being, that with No. 4 magnet there is, comparatively, a greater concentration of force at the wound pole, and that the opposite pole is longer and extends a littie way into the coil-the result of the coning of the wire. In these two cases the unwound end of the iron seems to act like an armature.

To ascertain the force which each magnet would exert on an armature, experiments were made and the following results obtained, the current flowing through the coil in each case being exactly the same, as well as the armature employed :-

Magnet.
No. 1
2
3
4

Weight required to detach the armature
from the covered end of the magnet.

45 ounces.

2

3

4
57 ,

57 "

77,

These results confirm those previously obtained, that the field produced by the covered ends of the electromagnets numbers 2 or 3 at distances near the pole is much stronger than that produced by No. 1. But they show something else, viz. that for very small distances it is the covered end of No. 4 that produces the strongest field. In other words, returning to fig. 5 , the curve $E E$, although much below the curves $A A, B B$, and $C C$, must rise rapidly and cut the others, just as the curve $C C$ cuts the curve $A A$, at a point corresponding with a distance of about 4.2 inches from the end of the magnet, and just as, again, the curve $B B$ cuts $A A$ at a point corresponding with a distance of about 3.2 inches from the end of the magnet. The curves of iron-filings (fig. 9) indeed give indication of the great strength and concentration of field there is produced close to the iron by the wire coned at the end, as employed in the magnet No. 4.

With, then, a definite iron core, a definite length of wire to be coiled on it, and to be traversed with a definite current, the mode of coiling to produce the largest field depends entirely on the distance from the end of the electromagnet at which the field is to be produced. With the particular magnet we

VOL. V. 
have employed we sce that, at distances from the end of the magnet rery small compared with the length of the core, the wire should all be coiled up at the near end of the core, as in fig. 4 ; to create a field at a distance from the end of the magnot equal to about a third of the length of the magnet, it is butter to coil the wire uniformly orer one half of the core, as in fig. 2, than to cone it up at the near end as in 4 ; while for distances from the end of the magnet equal to, or grenter than, about $\frac{f}{3}$ of the length of the core, the uniform mode of winding is the best.

Wo bave to thank two of our students, Messrs. Sayers and Pink, for most cordial assistance rendered us in this inrestigrition.

XXVII. Eivperiments on the Viscosity of a Solution of Saponine. By W. H. Stables and A. E. Wilson, Yorkshire College, Leeds*.

M. Plateau has shown (Statique des Liquides, t. 2, ch. vii.) that $a$ body placed in a liquid and wetted on one side only, experiences in many cases a greater resistance to its motion thim if it were completely immersed. Some controversy has arisen between Marangoni and himself as to the cause of this phenomenon, which M. Plateau explains by the assumption that the liquids in question possess a surface viscosity greater than that of the interior. The liquid in which the surface resistance is in most striking contrast to that of the interior is a solution of saponine in water.

Oberbeck (Wiedemann Annaler, Bd. 11, S. 634) has repeated and extended Plateau's experiments, using an oscillating disk instead of a magnetic needle. He made no observations upon saponine solution. The object, therefore, of the following investigation is to study the movements of a disk when oscillating in or near the surface of a solution of this substance.

Oberbeck found that the resistance of a water-surface increased largoly with exposure to the air ; but he aiso proved that eren with fresh distilled water the resistance is considerable. As he points out, we are therefore led to one of

* Read April 14, 1883. 